\title{
LOCALIZATION OF GFDD4-1 EXPRESSED PROTEIN IN Physcomitrella patens CELLS
}

\author{
DIAHRATNADEWI \\ Faculty of Mathematics and Natural Sciences, Bogor Agricultural University, Bogor, Indonesia
}

\begin{abstract}
The expression of a new dehydration-related gene of Physcomitrella patens, GFDD4-I, was traced for its localization in the plant cells. This revelation is useful to predict the possible roles of the protein in plant tolerance to environmental stress. This gene was fused to $g f p$ marker gene and transfected into the plant protoplasts. Under a confocal laser microscope, it was detected that the GFDD4-1 protein associated with the OFF started to generate at the cell periphery and developed more intensively inwards to cytoplasm, forming vesicles and cystemal structures or network. The protein might be membrane protein which may involve directly in membrane maintenance or cellular protection against stress conditions.
\end{abstract}

Key words : Protoplast transformation, protein localization, dehydration-related gene, GFP, Physcomitrella patens

\section{INTRODUCTION}

Abiotic stress leads to a series of morphological, physiological, biochemical and molecular changes that adversely affect plant growth and productivity. Diverse environmental stresses often activate a number of cell signalling pathways and cellular responses, such as production of stress proteins, up-regulation of antioxidants and accumulation of compatible solutes (Vierling and Kimpel 1992). In plant species which is tolerant to a stressing condition, the metabolic responses activated in response to the stress may contribute to the mechanism of tolerance. The production of heat-shock proteins (Hsps) and chaperons (Ingram and Bartels 1996; Bray et al. 2000), osmoprotectants and free-radical scavengers (Bohnert and Sheveleva 1998) are among the examples of substances that may involve in the protection of cell membranes and proteins.

Physcomitrella patens is a bryophyte which was reported to be highly tolerant to various abiotic stresses, in particular to salt, osmotic, and dehydration stresses (Frank et al. 2005). Genes PpSHPl and PpSHP2 in P. patens which demonstrate homology to RCI2A and RCI2B , respectively, of Arabidopsis thaliana, encoding highly conserved small hydrophobic proteins, have been confirmed to be up-regulated by desiccation, salt, sorbitol, cold, and abscisic acid (Kroemer et al. 2004), while an original dehydration related gene of P. patens, GFDD4J(Genefishmg Differential Display clone 4-1), demonstrated to be activated additionally by cold and ABA (Ratnadewi and Frank 2005). This indicated that $P$. patens has a number 
of genes regulated by those diverse stress conditions conferring its high level ot tolerance, and whose pathways are overlapping and complementary one to the other. Under light stress condition, Sepl and Sep2 encoded proteins (stress-enhanced proteins, Seps) in A. thaliana have been detected to localize in thylakoid membrane of chloroplasts; they might function in one or another way as plant protector to high-intensity light and are not likely light harvesting (Heddad and Adamska 2000). By attaching the open reading frame of the gene GFDD4-1 to gfp marker gene, we attempted to investigate the localization of the encoded protein in $P$ patens cells, The protein site may indicate its possible function in plant tolerance tc environmental stress.

\section{MATERIALS AND METHODS}

\section{Isolation}

\section{of cDNAs}

This research employed copy DNA of the GFDD4-1 gene. Searching of cDISM clones was carried out in the PpEST database (BASF-Albert Ludwigs University o: Freiburg) (Rensing el al 2002) using GFDD4-1 gene sequence as query. The cDNj* cloned in bacterial cultures have been retrieved as glycerol stocks from the clom depository. The clones were subject to PCR reactions, sequencing and selection foi the full length one.

\section{Plasmid reconstruction}

The coding region of the selected cDNA clone was amplified througl PCR reactions. The primers used were supplemented with $\mathrm{BamHI}$ at the 5 prime and with $\mathrm{Kpnl}$ at the 3 ' prime: the forward primer wa 5'-GGATCCATGAATTCCGAGGGTCTT-3' and the reverse primer wa 5'GGTACCATGACCACCACGACTATTC-3' to obtain the expected DW fragment size of about 600 bp. The PCR product was subsequently loaded on ai agarose gel $\left(1.0 \% \mathrm{wv}^{\prime 1}\right)$ and the appropriate band was isolated using QIAEXI purification kit for gel extraction (Qiagen). The cloning of the DNA fragment wa performed in pCR*4-TOPO* vector (Invitrogen), and the DNAs were then harvestei and purified through mini-preparation procedure (Qiagen). When the concerne $<$ fragment would be used as insert, digestion by BamHI and Kpnl followed by DM; isolation and purification using QIAEXII kit were executed again.

Plasmid pMAV4 contains gfp gene and was selected as vector to fuse the DN/ fragment to the reporter gene. It was linearized at the $\mathrm{BamHl}$ and $\mathrm{Kpnl}$ sites whei the DNA fragment would be inserted (Figure 1).The ligation was executed with T-DNA ligase (MBI Fermentas). 35S promoter drove the expression of these tandei genes. 


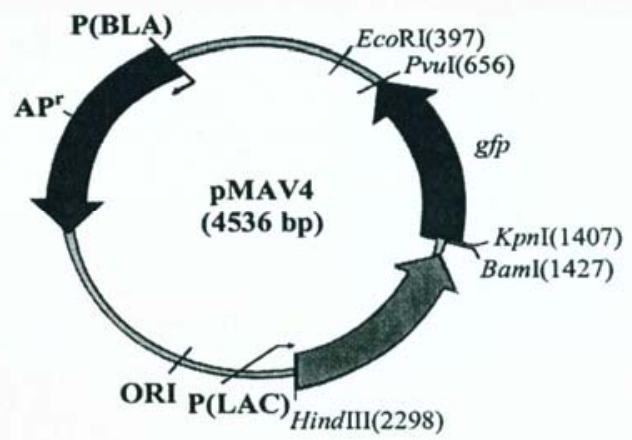

Figure 1. Map of pMAV4 plasmid showing the insertion site between BamHI and KpnI of the 600 bp fragment of GFDD4-1.

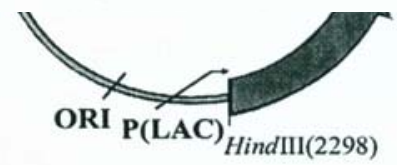

Figure 1. Map of pMAV4 plasmid showing the insertion site between BamHI and $\mathrm{KpnI}$ of the $600 \mathrm{bp}$ fragment of GFDD4-1.

\section{Bacterial transformation}

Escherichia coli competent cells clone XL1 Blue MRF" (100 uL) were proceeded for transformation by inoculating the new pMAV4 plasmid construct ( 2 to $8 \mathrm{uL}$ ). The bacterial mixture was incubated on ice (30 seconds), in water bath at $42^{\circ} \mathrm{C} \mathrm{(90} \mathrm{seconds)} \mathrm{and} \mathrm{on} \mathrm{ice} \mathrm{again} \mathrm{(2}$ $\mathrm{min})$. One millilitre of $\mathrm{LB}$ medium was added to the mixture prior to incubation in $37^{\circ} \mathrm{C}$ shaking water-bath for one hour. An amount of 100 ul of the transformed bacteria was plated on LB+amphycilin agar medium (Sambrook and Russel 2001). The rest was spinned down at $5000 \mathrm{rpm}$ for $3 \mathrm{~min}$; most of the supernatant was removed and the more concentrated solution was spread over a fresh medium of the same composition. Bacterial colonies were expected to grow after an overnight incubation at $37^{\circ} \mathrm{C}$. The appropriate ligated plasmid was isolated through DNA maxi-preparation (Qiagen) from a single colony derived cell suspension.

\section{Protoplasts isolation and transformation}

Moss plants at protonema stage were harvested from $200 \mathrm{ml}$ bioreactor liquid culture, which corresponds to about $10 \mathrm{mg}$ dry weight. Aseptically the moss was proceeded for protoplasts isolation according to the protocol described by Rother et al. (1994) with slight modification.

In a glass tube, $100 \mathrm{ul}$ of DNA solution $\left(0.5 \mathrm{ug} \mathrm{ul} \sim\right.$ in $\left.\mathrm{Ca}\left(\mathrm{NO}_{3}\right)_{2}\right)$ was added to $250 \mathrm{ul}$ of protoplast solution $\left(1.2 \times 10^{*}\right.$ protoplasts $\left.\mathrm{ml}^{\prime \prime}\right)$; 350 ul of PEG 4000 solution $(40 \%)$ was then incorporated into the mixture. It was mixed gently by rolling the tube between fingers. The subsequent procedure followed exactly the method cited in Hohe et al. (2003). The transformed protoplasts were re-suspended in $3 \mathrm{ml}$ of regeneration medium. It comprised $0.25 \mathrm{gl}^{\prime 1} \mathrm{KH}_{2} \mathrm{PO}_{4}, 0.25$ $\mathrm{el}^{1} \mathrm{KC} 1,0.25 \mathrm{gr}^{1} \mathrm{MgSO}_{4}-7 \mathrm{H}_{2} \mathrm{O}, 1 \mathrm{gr}^{1} \mathrm{Ca}\left(\mathrm{NO}_{3}\right)_{2}, 12.5 \mathrm{mgl}^{1} \mathrm{FeSO}_{4}-7 \mathrm{H}_{2} \mathrm{O}, 50 \mathrm{gP}$ and $30 \mathrm{gl}^{1}$ mannitol. The $\mathrm{pH}$ of the medium was adjusted to 5.8 with $\mathrm{KOH}$ and its osmolarity to 
approximately $540 \mathrm{mOs}$ using mannitol. The protoplast solution $(1.5 \mathrm{ml})$ was transferred into $3 \mathrm{~cm}$-well of culture plate. The protoplast cultures were incubated under dim-light at $25^{\circ} \mathrm{C}$. Observations were carried out at 1,2, 4, and 8 days after transfection. Transgenic cells were detected visually under a UV light microscope. When the expected green fluorescent intact cells were visible, the images were taken in more detail under a confocal laser scanning microscope.

\section{RESULTS AND DISCUSSION}

cDNA isolation and plasmid reconstruction

From searching in the PpEST database with GFDD4-1 gene sequence as query, three hits came out from there, e.g. clones no. PPOO1088038, PP004071329 and PP004083128. The three cDNA clones were retrieved from the depository to proceed to PCR for amplification using standard primers Ml3-20 and M13-rev. DNA sequencing revealed that the clone PP004071329 is the full-length cDNA and was used further in this work.

By using BamHl and Kpnl, insert of 600 bp DNA fragment and linearized pMAV4 were obtained prior to their ligation to a new construct. Figure 2 demonstrates the PCR products resulted from these digestions.

\section{GFDD4-1/GFProteins in transformed cells}

One day after the transfection, few green protoplasts were already seen under UV-light microscope, and they looked multiplying in number and intensity over the days of observation. The green fluorescence was assumed to be the protein expressed by the $g f^{\prime} p$ gene that was closely associated to the GFDD4-1. It has been proven that the intrinsic fluorescence of GFP allows for non-invasive and monitoring to track the expression and location of proteins and other structures within cells or organism without killing or destroying the biological samples. This makes GFP efficient as a transformation marker.

At the first till the fourth day, the green structures scattered unevenly along the periphery of the cells (Figure 3). Chloroplasts are represented by the red auto fluorescence; it was obvious that the protein was not generated in the plastid membrane. When a barrier filter was used to block the red fluorescence of chlorophyll, typical green fluorescence appeared more clearly. At the fourth and eighth day, the protein was more abundant, extending into the cytoplasm, forming vesicles and cysternal structures in some cases, and in some other cells it formed a network. 

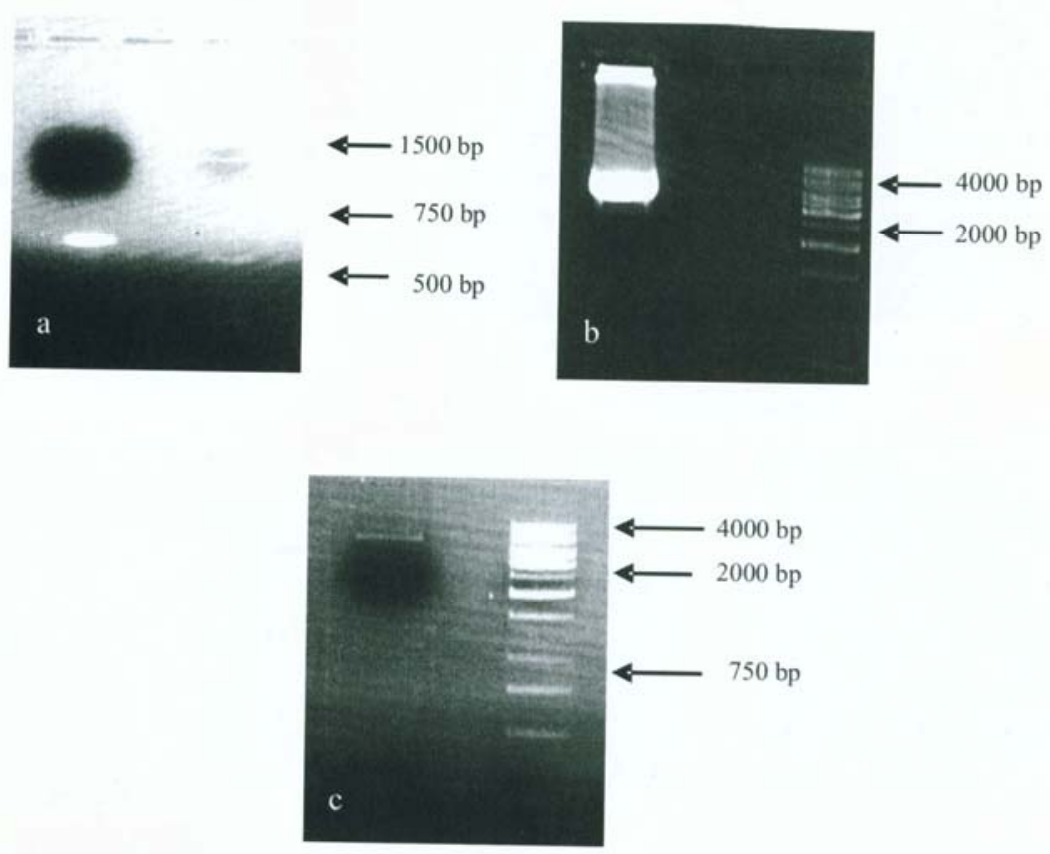

Figure 2. PCR products demonstrating the excision of DNA fragment by BamHI and KpnI.(a). 600 bp of insert candidate of GFDD4-1, (b). linearized pMAV4 plasmid (4016 bp), (c). new construct (4616 bp).

Abiotic stresses such as drought, salinity, cold, or heat are often interconnected and cause disruption of osmotic and ionic homeostasis as well as damage of functional and structural proteins and membranes (Wang et al. 2003). Plant responses to abiotic stress are quite complex due to the fact that, in one hand, it involves many genes and biochemical-molecular mechanisms, on the other hand, different stressing stimuli can induce only a single gene. In their response to environmental stresses, plants activate a large set of genes leading to the accumulation of specific stress-associated proteins.

The product of stress-related genes can be classified into two major categories: 1). Those that directly involve in the cellular protection against environmental stresses, such as Hsp and LEA proteins and chaperons, various osmo-protectants and detoxification enzymes, 2). Those that play roles in signalling cascades and in transcriptional control, such as transcription factors and protein kinase (Seki el al. 2003; Wang ef a/. 2003). 


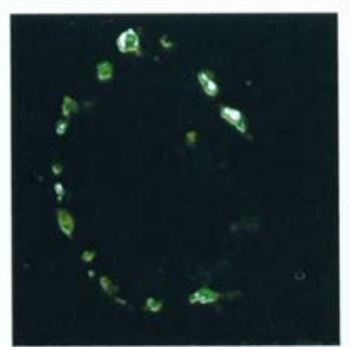

$2^{\text {nd }}$ day (i)

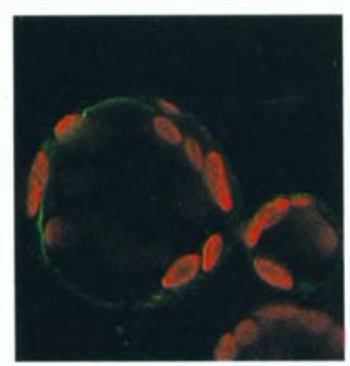

$4^{\text {th }}$ day (ii)

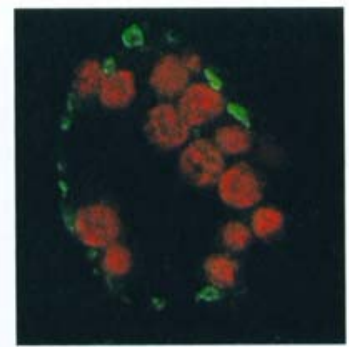

$2^{\text {nd }}$ day (ii)

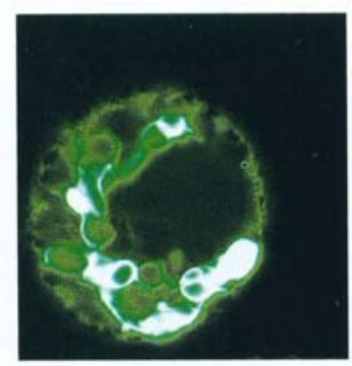

$8^{\text {th }}$ day (i)

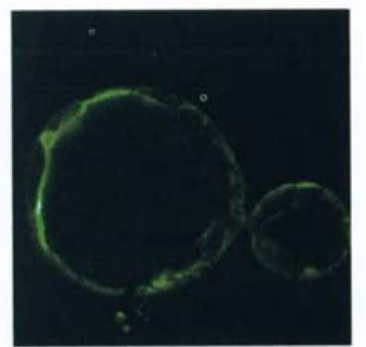

$4^{\text {th }}$ day (i)

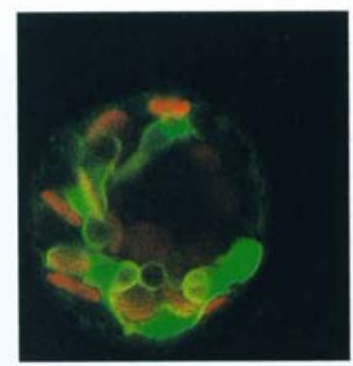

$8^{\text {th }}$ day (ii)

Figure 3. GFDD4-1/GFProtein localization in $P$. patens cells observed at the second, fourth, and eighth day after transfection under a confocal laser microscope. Green: GFDD4-1/GFP protein (i); red: chloroplast (ii)

Upon water, salinity, and/or extreme temperature stress, plants produce predominantly Hsps and LEA proteins. Hsp70s are found in several cellular compartments such as in cytoplasm, in the lumen of endoplasmic reticulum (ER), in the matrix of mitochondria, as well as in chloroplasts. They have been shown to act as molecular chaperons that function in the stabilization of proteins and membranes, and in assisting protein refolding under stress conditions (Vierling 1991). Accordingly, in this preliminary work, the GFDD4-1 protein associated to the GFP was observed spreading intensively over the cell. The protein in the peripheral area and the structures of vesicles and cysternae exhibited that the protein might be membrane protein which may involve in membrane maintenance or cellular protection against stress conditions.

\section{CONCLUSIONS}

The GFDD4-1, a dehydration-related protein in Physcomitrella patens, locates at cell membranous system. It may function directly or indirectly in cellular protection against environmental stresses. 


\section{ACKNOWLEDGEMENT}

The author would like to gratefully acknowledge the German Academic Exchange Service (DAAD) for the great opportunity given to do a part of her research in Germany. High appreciation also goes to Prof. Dr. Ralf Reski and Dr. Wolfgang Frank who permitted me to join their research group at the Institute of Plant Biotechnology, Albert-Ludwigs University of Freiburg.

\section{REFERENCES}

Bohnert, H.J. and E. Sheveleva. 1998. Plant stress adaptations - making metabolism move. Curr. Opin. Plant Biol., 1:267274.

Bray, E.A., J. Bailey-Serres and E. Weretilnyk. 2000. Responses to abiotic stresses. In: Gruissem W., Buchanan B., Jones R. (ed). Biochemistry and Molecular Biology of Plants. Rockville MD: Amer. Soc. Plant Physiologists, p. 11581249.

Frank, W., D. Ratnadewi and R. Reski. 2005. Physcomilrella patens is highly tolerant against drought, salt and osmotic stress. Planta, 220:384-394.

Heddad, M. and I. Adamska. 2000. Light stress-regulated two-helix proteins in Arahidopsis thaliana related to the chlorophyll a/2>-binding gene family. PNAS 97(7):3741-3746.

Hohe, A., T. Egener, J.M. Lucht, H. Holtorf, C. Reinhard, G. Schween and R. Reski. 2003. An Improved and highly standardised transformation procedure allows efficient production of single and multiple targeted gene-knockouts in a moss, Physcomitrella patens. Curr. Gen., 44:339-347.

Ingram, J. and D. Bartels. 1996. The molecular basis of dehydration tolerance in plants. Annu. Rev. Plant Biol., 47:377-403.

Kroemer, K., R. Reski and W. Frank. 2004. Abiotic stress response in the moss Physcomitrella patens: evidence for an evolutionary alteration in signaling pathways inland plants. Plant Cell Rep., 22:864-870.

Ratnadewi, D. and W. Frank. 2005. Ekspresi gen GFDD4-1 pada Physcomitrella patens dan gen homolog pada Arahidopsis thaliana dalam responsnya terhadap cekaman Abiotik. Hayati, 12(4):127-130.

Rensing, S.A., S. Rombauts, Y. Van de Peer and R. Reski. 2002. Moss transcriptome and beyond. Trends Plant Sci., 7:535538.

Rother, S., B. Hadeler, J.M. Orsini, W.O. Abel and R. Reski. 1994. Fate of a mutant macrochloroplasts in somatic hybrids. J. Plant Physiol., 143:72-77.

Sambrook, J. and D.W. Russel. 2001. Molecular cloning: A laboratory manual 3'" ed. Cold Spring Harbor: Cold Spring Harbor Laboratory Press.

Scki, M., A. Kamei, K. Yamaguchi-Shinozaki and K. Shinozaki. 2003. Molecular responses to drought, salinity and frost: common and different paths for plant protection. Curr. Opin. Biotech., 14:194-199.

Vierling,E. 1991. The roles of heat-shock proteins in plants. Annu. Rev. Plant Biol., 42:579-620.

Vierling, E and J.A. Kimpel. 1992. Plant responses to environmental stress. Curr. Opin. Biotech., 3:164-170.

Wang, W., B. Vinocur and A. Altaian. 2003. Plant responses to drought, salinity and extreme temperatures: towards genetic engineering for stress tolerance. Planta, 218:1-14. 